\title{
Translamellar Disinhibition in the Rat Hippocampal Dentate Gyrus after Seizure-Induced Degeneration of Vulnerable Hilar Neurons
}

\author{
Colin A. Zappone and Robert S. Sloviter \\ Departments of Pharmacology and Neurology, and the Graduate Program in Neuroscience, University of Arizona College of Medicine, Tucson, Arizona \\ 85724
}

\begin{abstract}
Longitudinally restricted axonal projections of hippocampal granule cells suggest that transverse segments of the granule cell layer may operate independently (the "lamellar" hypothesis). Longitudinal projections of excitatory hilar mossy cells could be viewed as antithetical to lamellar function, but only if longitudinal impulse flow effectively excites distant granule cells. We, therefore, determined the effect of focal granule cell discharges on granule cells located $>2 \mathrm{~mm}$ along the longitudinal axis. During perforant pathway stimulation in urethane-anesthetized rats, passive diffusion of the $\mathrm{GABA}_{\mathrm{A}}$ receptor antagonist bicuculline methiodide from the tip of a glass recording electrode evoked granule cell discharges and c-Fos expression in granule cells, mossy cells, and inhibitory interneurons, within a $\sim 400$ $\mu \mathrm{m}$ radius. This focally evoked activity powerfully suppressed distant granule cell-evoked responses recorded simultaneously $\sim 2.5-4.5$ mm longitudinally. Three days after kainic acid-induced status epilepticus or prolonged perforant pathway stimulation, translamellar inhibition was intact in rats with $<40 \%$ hilar neuron loss but was consistently abolished after extensive $(>85 \%)$ hilar cell loss. Retrograde transport of Fluoro-Gold (FG) from the rostral dentate gyrus revealed that few inhibitory interneurons were among the many retrogradely labeled hilar neurons 2.5-4.5 mm longitudinally. Although many somatostatin-positive hilar interneurons effectively transported FG from the distant septum, few of these neurons transported detectable FG from much closer hippocampal injection sites. Inhibitory basket and chandelier cells also exhibited minimal longitudinal FG transport. These findings suggest that translamellar disinhibition may result from the loss of vulnerable, longitudinally projecting mossy cells and may represent a network-level mechanism underlying postinjury hippocampal dysfunction and epileptic network hyperexcitability.
\end{abstract}

Key words: lamellar hypothesis; inhibitory interneurons; hippocampus; epilepsy; c-Fos; lateral inhibition

\section{Introduction}

Despite decades of study, the nature of the three-dimensional functional organization of the mammalian hippocampus remains controversial. The lamellar hypothesis posits a system in which focal excitation is conveyed sequentially to target neurons within functionally separated slices or "lamellae" (Andersen et al., 1971, 2000; Moser and Moser, 1998; Hampson et al., 1999). Conversely, the existence of excitatory, longitudinally projecting associational pathways has been suggested to be fundamentally antithetical to the concept of lamellar function, because these projections presumably spread excitation longitudinally and are, therefore, inconsistent with independent segmental operation (Amaral and Witter, 1989). In the dentate gyrus, longitudinally projecting hilar mossy cells have been suggested to be an excitatory link that interconnects distant segments of the granule cell layer (Buckmaster and Schwartzkroin, 1994). However, the avail-

Received July 18, 2003; revised Nov. 25, 2003; accepted Nov. 25, 2003.

This work was supported by National Institutes of Health Grant NS18201. We thank Dr. Hemant Kudrimoti for constructive criticism of this manuscript.

Correspondence should be addressed to Dr. R. S. Sloviter, Department of Pharmacology, University of Arizona College of Medicine, 1501 North Campbell Avenue, Tucson, AZ 85724-5050. E-mail: sloviter@u.arizona.edu.

DOI: 10.1523/JNEUROSCI.1619-03.2004

Copyright $\odot 2004$ Society for Neuroscience $\quad 0270-6474 / 04 / 240853-12 \$ 15.00 / 0$ able physiological data suggest that the net effect of mossy cell discharges may be translamellar inhibition, rather than excitation. Although hilar mossy cells innervate granule cell dendritic spines (Buckmaster et al., 1996), direct excitation of mossy cells in vitro inhibits granule cells disynaptically via excitation of inhibitory interneurons (Scharfman, 1995). Even when slices were bathed in bicuculline, mossy cell discharges only weakly depolarized granule cells (Scharfman, 1995). These in vitro data are consistent with previous in vivo studies showing that activation of excitatory commissural fibers had a net inhibitory effect on contralateral granule cells via excitation of contralateral inhibitory interneurons (Buzsáki and Eidelberg, 1982; Douglas et al., 1983). Thus, despite a numerically extensive innervation of granule cell dendritic spines, mossy cell excitation of inhibitory interneurons (Wenzel et al., 1997; Sloviter et al., 2003) may dominate functionally. Therefore, excitatory associational projections may constitute a disassociative system that establishes lateral inhibition and lamellar functional segregation within the granule cell layer (Sloviter, 1994; Sloviter and Brisman, 1995).

In this study, we have determined for the first time the nature of the influence of focal granule cell discharges on distant granule cells located $\sim 2.5-4.5 \mathrm{~mm}$ along the longitudinal axis. This distance is important because mossy cell axons minimally innervate 
the $\sim 1 \mathrm{~mm}$ radius around their somata, which inhibitory neurons preferentially target (Buckmaster et al., 1996), and because the associational projections of mossy cells preferentially target the dentate inner molecular layer beginning $\sim 1.2 \mathrm{~mm}$ in the septal direction from an anterograde tracer injection (Amaral and Witter, 1989). Furthermore, the total septo-temporal distance traversed by granule cell axons is as far as $1.3 \mathrm{~mm}$ in the adult rat (Sutula et al., 1998; Buckmaster and Dudek, 1999). Thus, translamellar influences were assessed at distances that both (1) exclude those traversed by the mossy fibers, and (2) include those innervated by the longitudinal associational projections formed by excitatory hilar mossy cells. To address whether vulnerable hilar neurons are possible mediators of the observed translamellar influences, we performed the same experiments in animals with hilar cell loss produced by kainic acid (KA)-induced status epilepticus (SE) (Sloviter et al., 2003) or prolonged perforant pathway (PP) stimulation (Sloviter, 1987, 1991). Finally, we used the retrograde tracer Fluoro-Gold (FG) to determine which hippocampal neuron subpopulations have the requisite longitudinal axon projections to influence distant dentate segments directly.

\section{Materials and Methods}

Male Sprague Dawley rats (250-400 gm) were treated in accordance with guidelines set by the National Institutes of Health for the humane treatment of animals and approved by the University of Arizona Institutional Animal Care and Use Committee.

KA SE and PP stimulation. Rats were anesthetized briefly with ether, a small incision was made in the skin overlying the saphenous vein, and KA (9-12 mg/kg; 10 mg/ml saline; Ocean Produce International, Shelburne, Canada) or saline was injected intravenously. After the end of SE, animals were given saline periodically by subcutaneous injection, and apple slices were provided as a source of food and water in a combined, digestible form. Four saline-treated rats and 14 rats that survived KA-induced SE lasting 3-6 hr were subsequently evaluated as described below. Intermittent PP stimulation for $24 \mathrm{hr}$ was performed in six urethane-anesthetized rats to produce extensive hilar neuron loss throughout the dorsal hippocampus, as described previously (Sloviter et al., 2003). All stimulated animals received urethane at a dose of $1.25 \mathrm{gm} / \mathrm{kg}$ s.c. before the start of stimulation and were given additional doses of $0.25 \mathrm{gm} / \mathrm{kg}$ s.c. $\sim 8$ and $\sim 14 \mathrm{hr}$ later, to ensure the maintenance of surgical anesthesia throughout the procedure. This anesthesia regimen, involving urethane by the subcutaneous route, produced no lethality and full recovery within $1 \mathrm{~d}$ after the last urethane dose. After electrode removal, the incised area was washed with Betadine, and the skin was sutured using surgical staples. Animals were given saline periodically by subcutaneous injection and were kept warm during recovery from anesthesia.

Assessment of translamellar influences. Normal $(n=23)$, KA-treated $(n=14)$, saline-treated $(n=4)$, and PP-stimulated $(n=6)$ rats were anesthetized with urethane $(1.25 \mathrm{gm} / \mathrm{kg}$, s.c.) $3 \mathrm{~d}$ after saline or KA injection, or $3 \mathrm{~d}$ after the end of $24 \mathrm{hr}$ intermittent PP stimulation, and placed in a stereotaxic apparatus. The rectal temperature was maintained at $37.0 \pm 0.2^{\circ} \mathrm{C}$. A bipolar-stimulating electrode (NE-200; Rhodes Medical Instruments, Summerland, CA) was placed in the left angular bundle of the $\mathrm{PP}(\sim 4.5 \mathrm{~mm}$ lateral from the midline suture and immediately rostral to the lambdoid suture). Two glass recording microelectrodes were used to assess translamellar inhibition, one of which contained $10 \mathrm{~mm}$ bicuculline methiodide (BMI) dissolved in saline (Sigma, St. Louis, MO) and was attached to a Hamilton microsyringe, as described previously (Sloviter and Brisman, 1995). Although granule cell discharges were produced by passive leakage of BMI from the recording electrode tip (inner diameter, $\sim 50-80 \mu \mathrm{m}$ ), a microsyringe was used so that the BMI solution could be ejected just before insertion into the brain to ensure that the tip was open. The other recording electrode was filled with saline and attached directly to a microelectrode holder.
Translamellar influences were assessed by first lowering a saline-filled recording electrode into the hippocampus ( $\sim 2 \mathrm{~mm}$ lateral from the midline, $\sim 3 \mathrm{~mm}$ caudal to bregma, and $3.5 \mathrm{~mm}$ below the brain surface) at the approximate site of plate 32 in the atlas of Paxinos and Watson (1998). The final tip location in the dorsal blade of the granule cell layer was reached by observing the potentials evoked by PP stimulation (Andersen et al., 1966). Stimuli were biphasic current pulses (0.1 msec duration) generated by a Master 8 stimulator and stimulus isolation unit (Armon MicroProcessor Instruments, Jerusalem, Israel). Potentials were amplified, displayed on an oscilloscope (Nicolet 400), and recorded digitally at a $20-40 \mathrm{kHz}$ sampling rate (AD Instruments, Mountain View, CA). After optimization of the evoked potentials, we recorded at least 10 responses to paired-pulse stimulation at $0.3 \mathrm{~Hz}$ at an interpulse interval of $60 \mathrm{msec}$. During continuous PP stimulation at $0.3 \mathrm{~Hz}$, the BMIcontaining recording electrode was then lowered into the brain $\sim 2.5-4.5$ $\mathrm{mm}$ posterior to the saline-filled electrode along the longitudinal axis of the dentate gyrus at the location shown in plates 41 and 42 in the atlas of Paxinos and Watson (1998). A $60 \mathrm{msec}$ interpulse interval was chosen because normal rats do not exhibit suppression of the second population spike at a $60 \mathrm{msec}$ interval. Therefore, the second population spikes evoked in both control and experimental animals were of similarly large amplitudes before insertion of the BMI-filled recording electrode.

Retrograde transport of FG. The retrograde tracer FG (Fluorochrome, Englewood, CO) (Schmued and Fallon, 1986) was injected in naive rats in the same hippocampal location in which the saline-filled electrode was inserted in the physiological experiments $(n=9)$. This was done to determine which neurons at the distant BMI electrode site possess axonal projections capable of directly affecting neurons at the anterior saline electrode site. The methods used to inject FG have been described in detail previously (Zappone and Sloviter, 2001). In brief, under urethane anesthesia as described above, and after placement of the electrode tip in the dorsal blade of the granule cell layer under physiological guidance during PP stimulation, $20-30 \mathrm{nl}$ of a $4 \%$ solution of FG in saline was injected using a syringe/electrode identical to that used for BMI diffusion. For control comparisons, FG (20-30 $\mathrm{nl}$ of the same FG solution) was injected into the medial septum $(0-0.5 \mathrm{~mm}$ posterior to the bregma and $\sim 5 \mathrm{~mm}$ below the brain surface; $n=6$ ), the neocortex above the dentate injection site $(n=3)$, and the CAl region above the dentate injection site $(n=5)$. The injection electrode was left in place for $10 \mathrm{~min}$ after injection. After electrode removal, the skull was washed with Betadine, and the skin was sutured using surgical staples. Animals were allowed to survive for 7-21 d before perfusion fixation as described below. As illustrated previously, FG injection in the volumes we used deposited FG throughout the laminas of the dentate gyrus and the overlying area CA1 (Zappone and Sloviter, 2001). Thus, the FG injections encompassed all axonal termination zones in the dentate molecular, granule cell, and hilar layers and are not represented as being focal deposits of retrograde tracer in any specific hippocampal subregion.

Perfusion fixation and tissue treatment. After $1 \mathrm{hr}$ of BMI-induced granule cell discharges at the posterior recording site, all electrodes were removed, and the distance between the BMI and saline electrode tips was measured. In 11 additional rats, electrodes were removed after $7 \mathrm{hr}$ of BMI-induced discharges, a duration used to determine whether prolonged discharges would evoke c-Fos expression in distant target cells. All animals were perfused with saline for $2 \mathrm{~min}$, then $4 \%$ paraformaldehyde in $0.1 \mathrm{~m}$ phosphate buffer, $\mathrm{pH} 7.4$, for $10 \mathrm{~min}$. After storage of the intact rat overnight at $4^{\circ} \mathrm{C}$, brains were removed from the skull and placed in perfusate. Coronal sections, $40 \mu \mathrm{m}$ thick, were cut on a Vibratome in 0.1 M Tris buffer, $\mathrm{pH}$ 7.6. Sections were mounted on gelatin- and chrom alum-coated slides for subsequent Nissl (cresyl violet) staining or for staining acutely degenerating neurons with Fluoro-Jade B (Schmued and Hopkins, 2000). After staining, all slides were dehydrated in graded ethanols and xylene and then coverslipped with Permount or DPX [solution of distyrene, a plasticizer (BPS-butylpthalatestyrene), and xylene] (for Fluoro-Jade B).

For immunocytochemistry, sections were mounted on Superfrost Plus slides, air dried for $15 \mathrm{~min}$, placed in $0.1 \mathrm{M}$ Tris buffer, $\mathrm{pH}$ 7.6, and processed as described in detail previously (Sloviter et al., 2003). The antisera used included rabbit anti-c-Fos (Ab H125; 1:5000 dilution; 

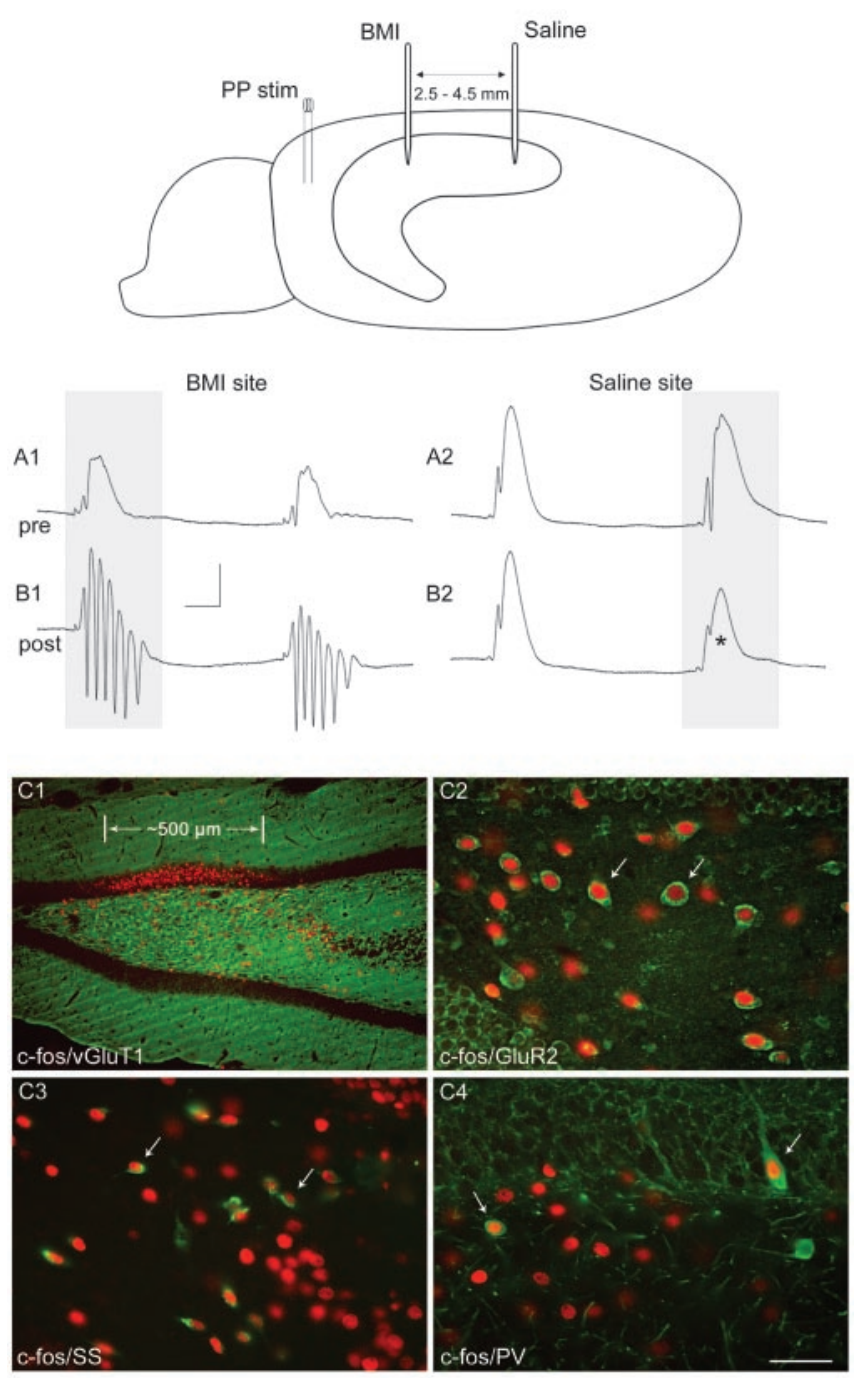

Figure 1. Translamellar inhibition in the normal rat dentate gyrus under urethane anesthesia. The influence of focal granule cell discharges evoked at a BMI-filled recording electrode in response to slow $(0.3 \mathrm{~Hz})$ PP stimulation (PP stim) was assessed simultaneously at a distant segment of the granule cell layer via a saline-filled recording electrode. $A 1, A 2$, Before passive leakage of BMI from the tip of a glass recording electrode, PP stimulation at $0.3 \mathrm{~Hz}$ simultaneously evoked single population spikes at both the BMI-filled ( $A$ 1; pre, pre-diffusion of BMI) and saline-filled (A2) recording electrodes, which were separated $\sim 3.5 \mathrm{~mm}$ along the longitudinal hippocampal axis. As BMI diffused from the tip of the BMI-filled electrode, the same afferent stimuli evoked multiple population spikes (post, post-diffusion of BMI) at the BMI site (B1) and simultaneously produced, at the saline electrode (B2), a selective inhibition of the second evoked response ( $A 2-B 2$, compare waveforms in the shaded box). Distant inhibition included suppression of both the negative-going population spike (asterisk) and the amplitude of the evoked fEPSP. C1, c-Fos immunoreactivity at the BMI site after $1 \mathrm{hr}$ of BMI-induced granule cell discharges, showing the extent of granule cell activation [region between arrows; c-Fos in red; vesicular glutamate transporter 1 (vGluT1) in green for contrast]. C2, Colocalization of c-Fos (red) and GluR2 (green). C3, c-Fos (red) and SS (green). C4, c-Fos (red) and PV (green). Note that c-Fos-expressing neurons include large GluR2-positive hilar neurons (presumed mossy cells) and SS- and PV-positive inhibitory interneurons. Rats were perfusion fixed $1 \mathrm{hr}$ after the end of the $1 \mathrm{hr}$ BMI diffusion. Calibration: $A 1-B 2,10 \mathrm{mV}$ and $10 \mathrm{msec}$. Scale bar: $C 1,200$ $\mu \mathrm{m} ; \mathrm{C2}_{-}(4,50 \mu \mathrm{m}$. Magnification: $\mathrm{C1}, 33 \times$; $2-C 4,130 \times$.

Santa Cruz Biotechnology, Santa Cruz , CA), rabbit anti-FG (AB153; 1:50,000; Chemicon, Temecula, CA), guinea pig anti-vesicular glutamate transporter 1 (Ab5905; 1:50,000; Chemicon), mouse anti-parvalbumin (PV) (P3171; 1:1,000,000; Sigma), mouse anti-somatostatin (SS) (V1169; 1:300; Biomeda, Foster City, CA), mouse anti-NeuN (MAB377; 1:10,000; Chemicon), and mouse anti-glutamate receptor subunit 2 (GluR2) (MAB397; 1:25,000; Chemicon). Images were acquired digitally

$$
\text { BMI Site }
$$

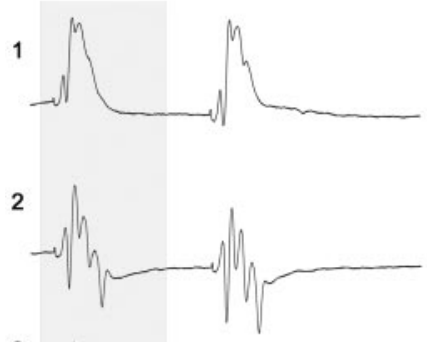

3

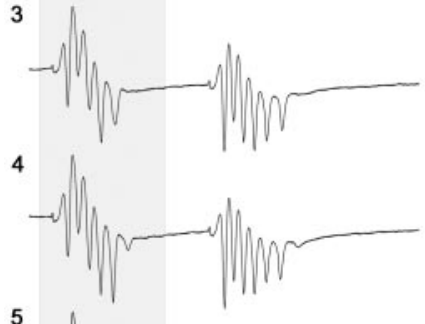

5

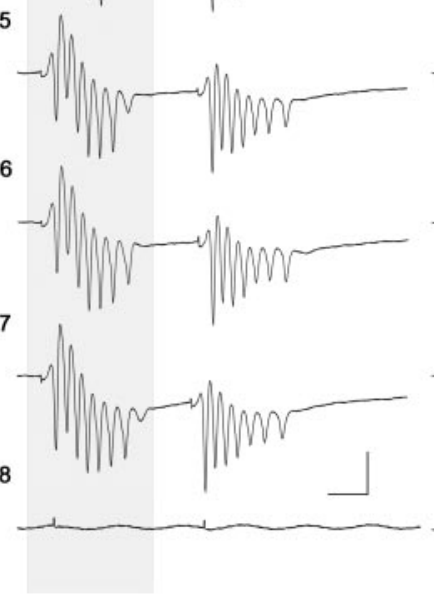

Distant Site

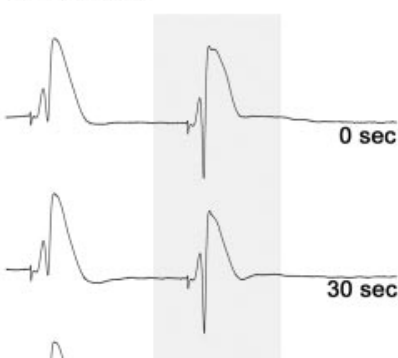

Figure 2. Progressive and reversible translamellar inhibition in the normal rat dentate gyrus. In this series of simultaneously recorded evoked responses to $0.3 \mathrm{~Hz} P P$ stimulation, diffusion of BMI from one recording electrode produced gradually increasing responses (multiple granule cell population spikes) to the same slow afferent stimuli. Coincident with these focal discharges recorded at the BMI-filled electrode (left shaded box), responses recorded simultaneously exhibited selective and progressive suppression of the second population spike and the fEPSP amplitudes (right shaded box). This selective inhibition of the second of two evoked responses at the saline-filled electrode was presumably initiated by the first of two discharges at the BMI-filled electrode, which required the interpulse interval to manifest its longitudinal influence. Note also that neither of the two multiple granule cell discharges at the BMI electrode evoked any detectable excitatory response after the second response recorded at the saline electrode site (arrowed line in trace 7). That is, no distant longitudinal excitatory influences of focal granule cell discharges were detected. Granule cell responses to PP stimulation recorded during the 10 min period after removal of the BMI-filled electrode from the granule cell layer (left trace 8) showed the decline of translamellar inhibition at the saline electrode (right trace 8), apparently reflecting recovery from the influence of the distant BMI-induced discharges as BMI was cleared from the tissue. Calibration, $5 \mathrm{mV}$ and $10 \mathrm{msec}$.

on a E800M microscope (Nikon) with C5180 camera (Hamamatsu, Middlesex, NJ), using Adobe Photoshop 7.0.

To determine the extent of hilar neuron loss at the BMI site in KAtreated and PP-stimulated rats, we selected three nonconsecutive Nisslstained sections from within the c-Fos-positive region of the BMI electrode. The numbers of surviving hilar neurons were counted in three sections from each animal and expressed as means \pm SEMs. Although hilar cell loss or survival was relatively uniform throughout the dorsal hippocampus, only sections at the BMI electrode site were assessed quantitatively for hilar neuron loss or survival, because the primary assumption of the experimental design was that it was the activated neurons at the BMI electrode site that mediated the distant effects of the focal gran- 
ule cell discharges. Statistical comparisons of spike suppression and hilar cell number were made using a Mann-Whitney $U$ test.

\section{Results}

\section{Translamellar influences in the normal} rat dentate gyrus

In normal $(n=12)$ and saline-treated $(n=4)$ control rats, paired-pulse stimulation of the PP (Fig. 1, drawing) at $0.3 \mathrm{~Hz}$ and an interpulse interval of $60 \mathrm{msec}$ evoked large amplitude population spikes at the saline-filled recording electrode that exhibited potentiation [i.e., the amplitude of the second of two evoked population spikes was larger than the amplitude of the first population spike (Fig. 1A2)]. While we continuously recorded these potentials at the saline electrode site, and without changing the stimulus parameters, the BMI-filled recording electrode was lowered into the granule cell layer $\sim 2.5-4.5$ $\mathrm{mm}$ along the longitudinal axis. Immediately after reaching the dorsal granule cell layer, and before any appreciable diffusion of BMI from the recording electrode tip, both the saline- and BMI-filled recording electrodes simultaneously recorded relatively normal evoked responses (Fig. $1 A 1, A 2)$. Within seconds, however, as BMI diffused from the recording electrode tip, the BMI-filled electrode began to record multiple population spikes (Fig.

$1 \mathrm{B1}$ ), and the distant saline electrode simultaneously recorded selective suppression of the second evoked population spike and field EPSP (fEPSP) (Andersen et al., 1966) amplitudes (Figs. 1 B2, 2 , trace 7 ). Figure 2 shows a series of evoked responses in a normal animal in which BMI apparently diffused relatively slowly from the tip of the BMI-filled recording electrode. This series of evoked potentials illustrates the gradually progressive and selective inhibition of the distant second granule cell population spikes (Fig. 2, right shaded box) caused by the first of two multiple discharges evoked at the BMI-filled recording electrode (Fig. 2, left shaded box). The selective inhibition of the second evoked response at the saline-filled electrode was presumably initiated by the first evoked discharge at the BMI-filled electrode and required the interpulse interval to manifest its longitudinal influence on the second evoked response at the distant site. Figure 2 also demonstrates the reversibility of the effect that occurred reliably at the saline electrode site within minutes after the BMI-filled electrode was removed (Fig. 2, bottom traces).

Focal granule cell discharges generated at the BMI electrode did not increase population spike amplitudes at the saline electrode in any animal tested $(n=16)$, nor did they evoke any detectable positive-going field potentials indicative of longitudinal excitation that was in any way comparable with even weak PP stimulation. That is, if the second of two multiple discharges recorded at the BMI-filled electrode produced a synchronous depolarization or discharge of the distant granule cells being simultaneously monitored at the saline electrode site, an evoked potential would presumably be detectable after the second evoked potential, during the period marked by the arrowed line in Figure 2, trace 7. Or, translamellar excitation would be ex-
A2 c-fos

(1)
-fos/PV
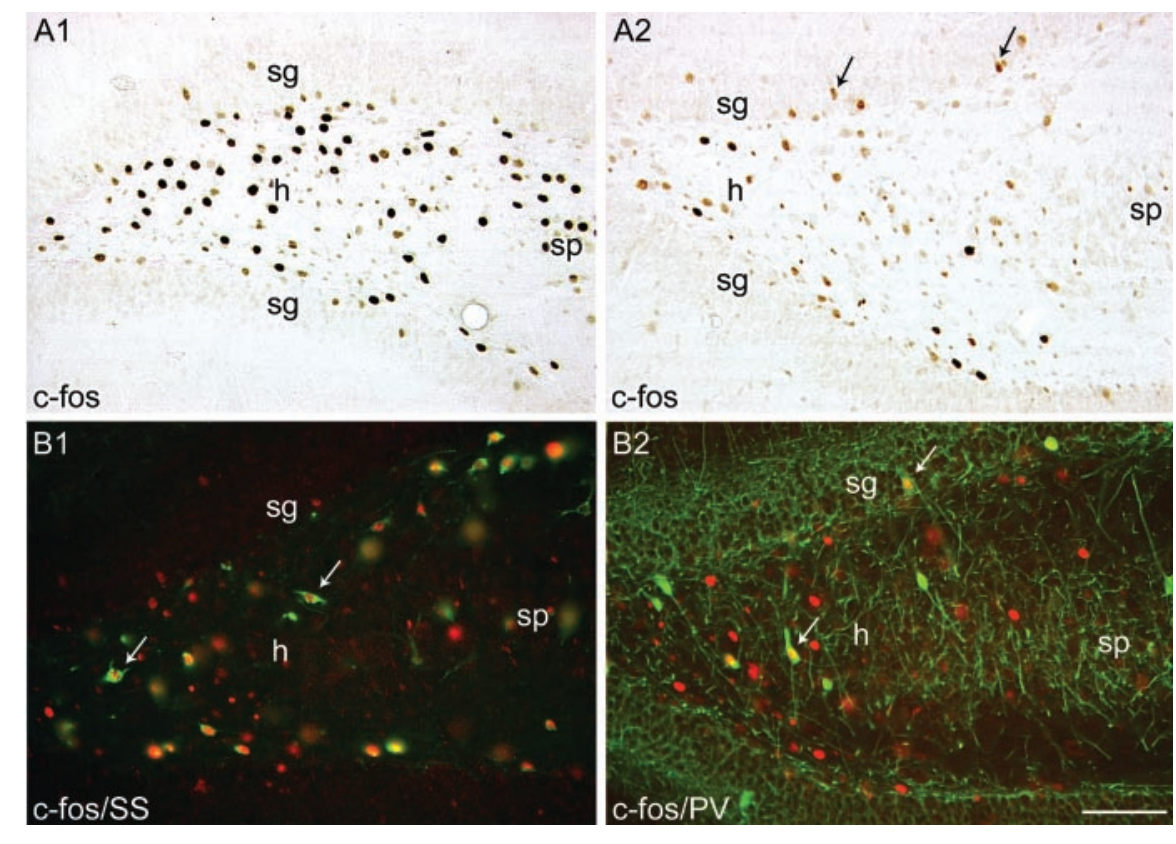

$\mathrm{sg}$
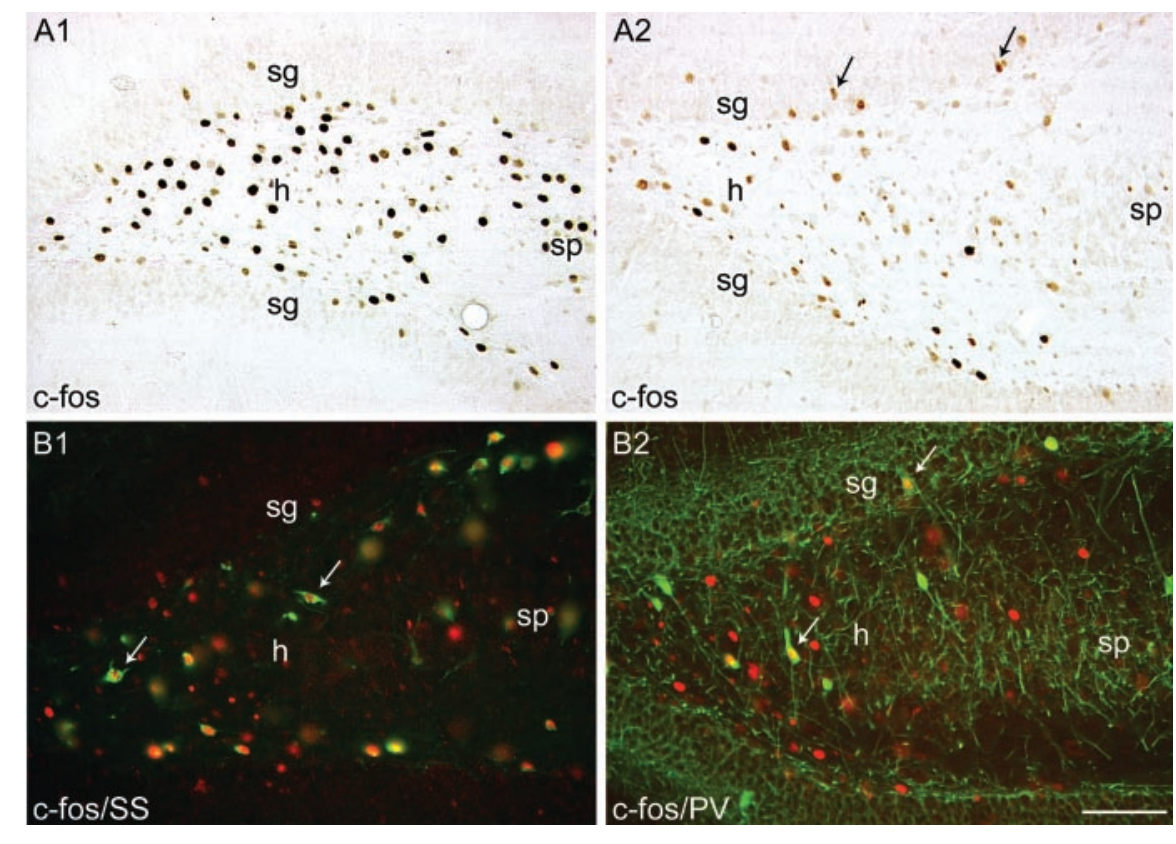

Figure 3. c-Fos expression beyond the region of focal granule cell activation evoked by BMI diffusion. A1, In sections $\sim 200-$ $400 \mu \mathrm{m}$ longitudinally from the outer edge of the granule cell c-Fos activation zone, c-Fos-positive cells included hilar neurons (h) and presumed interneurons of the granule cell layer $(\mathrm{sg})$. Note that the section shown in $A 1$ was $\sim 240 \mu \mathrm{m}$ from the outer edge c-Fos-positive granule cell layer. A2, Farther from the BMl electrode site $(\sim 3.6 \mathrm{~mm}$ longitudinally from the c-Fos-positive translamellar c-Fos expression, the distantly activated neurons included presumed basket cells of the granule cell layer and hilar SS- and PV-positive hilar interneurons but not distant dentate granule cells. Scale bar, $100 \mu \mathrm{m}$. Magnification, $97 \times$.

pected to increase the amplitude of the population spike, or produce multiple spikes, which are effects we never observed.

In a comparison of second spike suppression in control animals at different distances between the BMI- and saline-filled electrodes, no statistically significant difference in second spike suppression was observed between six controls, in which the mean distance between the electrodes was $4.03 \mathrm{~mm}$ (range, 3.604.89 ), and four other controls, in which the mean distance was $2.79 \mathrm{~mm}$ (range, 2.52-3.24). In these two groups, second spike suppression was $67.60 \pm 4.24 \%$ in the larger separation group and $73.90 \pm 10.13 \%$ in the smaller separation group. Thus, the magnitude of second spike suppression in control animals was not significantly different over the range of distances evaluated.

\section{c-Fos expression in normal rats after BMI-induced focal discharges}

c-Fos expression was assessed immunocytochemically to determine the extent of focal neuronal activation evoked at the BMIfilled recording electrode. BMI diffusion during slow $(0.3 \mathrm{~Hz})$ afferent stimulation consistently evoked c-Fos expression within a radius of $\sim 400 \mu \mathrm{m}$ from the electrode tip in all animals (Fig. 1C1) (range of diameter of c-Fos activation, 500-1050 $\mu \mathrm{m}$; mean, $798.8 \pm 78.2 \mu \mathrm{m} \mathrm{SEM} ; n=8)$. In addition to c-Fospositive granule cells, GluR2-positive dentate hilar neurons (presumed mossy cells) (Leranth et al., 1996) (Fig. 1C2) and SS- and $\mathrm{PV}$-positive inhibitory interneurons (Fig. 1, C3 and C4, respectively) were consistently c-Fos positive in the region surrounding the BMI electrode tip. c-Fos expression in the BMI diffusion zone was entirely dependent on afferent stimulation-induced granule cell discharges, because identical placement of the BMI electrode for $1 \mathrm{hr}$, in the absence of afferent stimulation, produced no 
detectable c-Fos expression greater than that produced in local granule cells by placement of a saline-filled glass electrode $(n=3$; data not shown). In these unstimulated control animals, an obstructed electrode lumen would not be detectable without delivery of afferent stimuli. Therefore, a single stimulus pair was delivered immediately before perfusion fixation to confirm that BMI had been diffusing from the electrode tip and that afferent stimuli would have evoked focal granule cell discharges during the preceding $1 \mathrm{hr}$ period had they been delivered.

c-Fos expression in dentate hilar neurons and presumed basket cells of the granule cell layer was consistently evident longitudinally, beyond the region of focal granule cell activation (Fig. $3 A 1)$. That is, at relatively short longitudinal distances from the outer limit of c-Fos-positive granule cells $(\sim 300-500 \mu \mathrm{m})$, hilar GluR2-, SS-, and PV-positive neurons were c-Fos positive. This occurred presumably as a result of mossy fiber activation of hilar neuron dendrites that extended into the mossy fiber axon projection zone from somata located slightly beyond this zone. We systematically evaluated c-Fos-immunostained sections at increasing longitudinal distances to determine whether focal granule cell discharges at the BMI-filled electrode evoked c-Fos expression in granule cells or nonprincipal cells farther along the longitudinal axis. Consistent with the lack of evidence of translamellar granule cell excitation, we noted no instance in which distant granule cells were c-Fos positive after $1 \mathrm{hr}$ of BMIinduced granule cell discharges. A separate group of normal animals $(n=11)$, in which the BMI electrode remained in place for $7 \mathrm{hr}$ before perfusion fixation, was used to increase the possibility of evoking c-Fos expression in distant target cells. Although we observed evidence of c-Fos expression in distant SS- and PVpositive inhibitory interneurons in a minority of animals $(\sim 2.5-$ $3.9 \mathrm{~mm}$ longitudinally from the edge of the c-Fos-positive BMI activation zone), which was consistent with the observed distantly evoked translamellar inhibition (Fig. 3A2,B1,B2), most animals exhibited no detectable c-Fos induction at the distant site of the saline-filled recording electrode. Thus, although distant c-Fos expression, whenever it was detected, was present only within inhibitory interneurons, this effect was observed in only 2 of 11 animals tested, and no other stimulation or duration parameters tested in pilot experiments $(0.3-2.0 \mathrm{~Hz} ; 1-20 \mathrm{hr}$ duration) were found to produce this effect consistently.

\section{Translamellar disinhibition in KA-treated and PP-stimulated rats}

Translamellar inhibition was assessed in 14 KA-treated rats, $3 \mathrm{~d}$ after all 14 had exhibited prolonged SE lasting at least $3 \mathrm{hr}$. This was done to determine whether prior hilar neuron loss would abolish BMI-induced translamellar inhibition. Analysis of each KA-treated animal, which was blinded in the sense that the extent of hilar neuron loss could not be known during the electrophysiological assessment, revealed two distinct responses to BMI diffusion. In 10 of the $14 \mathrm{KA}$-treated rats, BMI-induced granule cell discharges evoked relatively normal suppression of both the population spike and the fEPSPs recorded at the saline electrode (type 1 response) (Fig. 4A4; Table 1). However, in 4 of the 14 identically KA-treated rats, BMI-induced granule cell discharges produced minimal or no distant inhibition at the saline-filled electrode despite similar BMI-induced granule cell discharges (type 2 response) (Fig. 4B4; Table 1). Thus, the loss of translamellar inhibition in KA-treated rats seemed to be a relatively "all-ornone" phenomenon, with $10 \mathrm{KA}$-treated rats, appearing similar to normal animals, and 4 identically KA-treated rats nearly devoid of translamellar inhibition.

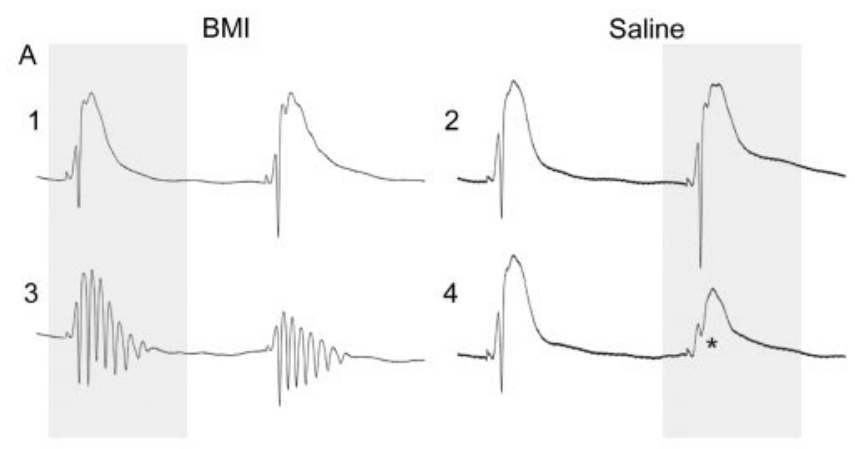

Kainate Type 2 Response

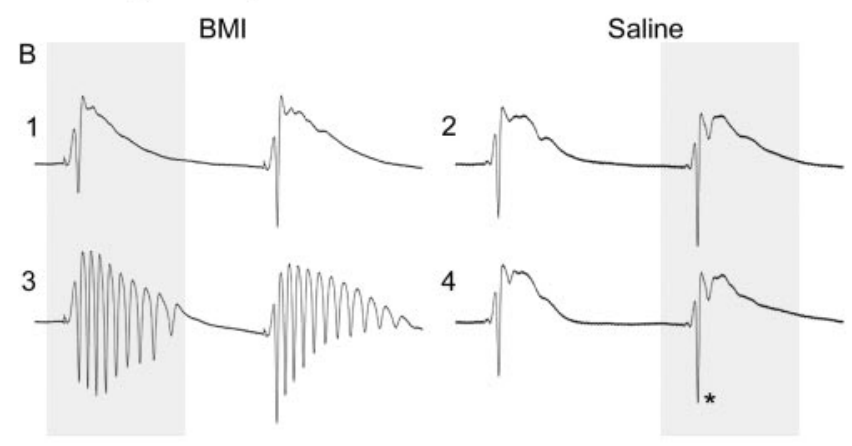

Perforant Path Stimulation

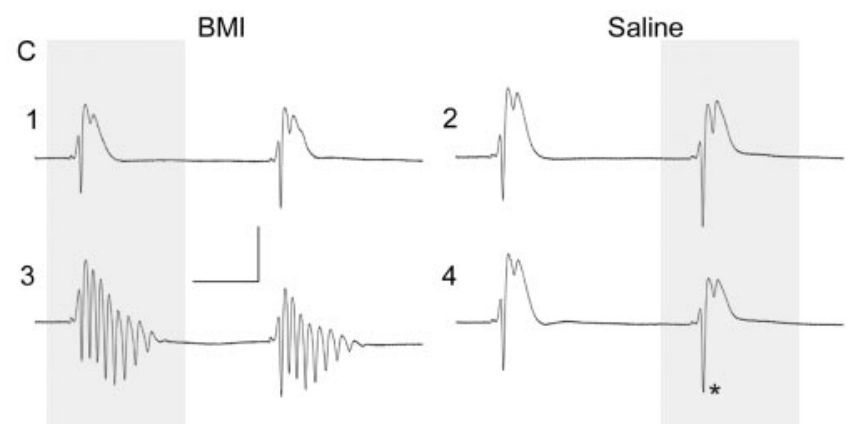

Figure 4. Translamellar inhibition or disinhibition $3 \mathrm{~d}$ after KA-induced SE or $24 \mathrm{hr}$ intermittent PP stimulation. A, KA type 1 response. Rats subsequently found to have an average of $20 \%$ fewer hilar neurons compared with controls (Fig. 5E) exhibited intact translamellar inhibition of the evoked granule cell population spike ( $A 4$, asterisk; $n=10)$. B, KA type 2 response. In rats subsequently found to have an average of $85 \%$ fewer hilar cells than controls (Fig. $5 E ; n=4$ ), BMI-induced discharges (B3) evoked minimal translamellar inhibition (B4, asterisk). C, Similar failure of translamellar inhibition in PP-stimulated rats (C4, asterisk), which exhibited an average of $93 \%$ fewer hilar cells (range, $89-95 \% ; n=6$ ) than controls (Fig. 5E). Calibration, $10 \mathrm{mV}$ and $10 \mathrm{msec}$.

Histological analysis (Fig. 5) revealed that, in KA type 1 rats (translamellar inhibition preserved), the number of hilar neurons counted in sections at the BMI electrode site was 20\% lower, on average, than controls (saline-treated controls, $62.8 \pm 12.0$ hilar neurons per section; $n=4$; KA type $1,50.0 \pm 3.5$ neurons per section; range, $10-38 \%$ fewer neurons; $n=10 ; p>0.05$ ), which was not statistically significant. In contrast, KA type 2 animals (translamellar inhibition abolished) exhibited an average hilar cell loss of $85 \%$, which was significantly different from type 1 rats and controls ( $9.5 \pm 3.7$ neurons per section; range, $68-94 \%$ fewer hilar neurons; $n=4 ; p<0.05$ ). Although the extent of hilar cell loss in the dorsal hippocampus was highly variable among identically treated KA rats, extensive CA3 pyramidal cell layer 
Table 1. Translamellar granule inhibition $3 \mathrm{~d}$ after KA-induced SE or $\mathbf{2 4}$ hr intermittent PP stimulation

\begin{tabular}{|c|c|c|c|c|}
\hline & Pre-BMI second spike amplitude (mV) & Post-BMI second spike amplitude (mV) & Percentage of second spike suppression & Distance between electrodes (mm) \\
\hline Control $(n=4)$ & $10.76 \pm 2.59$ & $2.62 \pm 1.11$ & $73.90 \pm 10.13$ & $2.79 \pm 0.17$ \\
\hline KA type $1(n=10)$ & $12.51 \pm 1.85$ & $2.34 \pm 0.47$ & $79.54 \pm 4.39$ & $2.70 \pm 0.13$ \\
\hline KA type $2(n=4)$ & $10.30 \pm 2.98$ & $9.84 \pm 3.04^{*,+++}$ & $5.71 \pm 2.77^{*++++}$ & $2.52 \pm 0.29$ \\
\hline 24 hr PP stimulation $(n=6)$ & $14.06 \pm 0.57$ & $13.78 \pm 0.62^{*,++++}$ & $1.92 \pm 1.86^{* *,++++}$ & $2.64 \pm 0.21$ \\
\hline
\end{tabular}

Significantly different from the control (*) and KA type 1 group (+) means: ${ }^{*} p<0.05 ;{ }^{* *} p<0.02 ;{ }^{+++} p<0.01 ;{ }^{++++} p<0.001$.

damage, ventral hippocampal hilar cell loss, and temporal cortex damage were present in both KA groups. Thus, only extensive dorsal hippocampal hilar neuron loss was consistently associated with a failure of BMI-induced granule cell discharges to evoke translamellar granule cell inhibition (Fig. 5E).

The close correlation between hilar neuron loss and translamellar disinhibition in KA-treated rats was also addressed in rats previously subjected to prolonged, unilateral PP stimulation, because this paradigm reliably produces extensive hilar cell loss throughout the dorsal hippocampus without involving behavioral SE or producing any significant extra-hippocampal damage (Sloviter, 1983, 1991; Sloviter et al., 2003). We reasoned that if dorsal hippocampal hilar cell loss per se caused the observed translamellar disinhibition in KA-treated rats, then PPstimulated rats with extensive, but relatively selective, hilar cell loss should exhibit the same loss of translamellar inhibition seen in the more extensively damaged KA type 2 animals.

Three days after the end of $24 \mathrm{hr}$ of intermittent PP stimulation, BMI-induced granule cell discharges failed consistently to evoke distant inhibition $(n=6)$ (Fig. 4C2,C4; Table 1). Compared with controls $(n=4)$, previously PP-stimulated rats exhibited an average of $93 \%$ fewer hilar neurons (4.6 \pm 0.7 hilar neurons per section; range, $89-95 \%$ fewer neurons; $n=6 ; p<0.01$ ) at the dorsal hippocampal BMI electrode site (Fig. 5D1,D2). Injury was also apparent in area CA3c of PP-stimulated animals (Fig. 6C1), but no obvious injury was detected in the temporal neocortex or in any other brain regions. Thus, unilateral $24 \mathrm{hr}$ intermittent PP stimulation, which has been shown previously to produce primarily unilateral hilar neuron loss (Sloviter, 1991), was as effective at abolishing translamellar granule cell inhibition as was widely brain-damaging KA-induced SE, when and only when it involved extensive hilar neuron loss. The complementary structural features of these two animal models that are most relevant to the pathophysiological results are illustrated in Figure 6, which contrasts a PP-stimulated rat with extensive hilar cell loss and no apparent extrahippocampal damage, with a KA-treated rat with minimal hilar cell loss but extensive brain damage. In contrast to the PP-stimulated animal, which exhibited a loss of translamellar inhibition (Fig. 6A1), the KA-treated rat with intact translamellar inhibition (Fig. 6B1) exhibited selective survival of hilar neurons (Fig. 6B2) but extensive damage to CA1 and CA3 pyramidal cells (Fig. 6B3,C1) and temporal cortical nuclei (Fig. 6C2). In Fluoro-Jade B-stained sections of this extensively damaged, KA-treated rat that exhibited intact translamellar inhibition, the only hippocampal region lacking acutely degenerating neurons was the dentate gyrus (Fig. 6C1, asterisk).

Figure 7 illustrates the correlation between hilar neuron loss at the BMI electrode site and the loss of translamellar inhibition. The clustering together of all 10 disinhibited animals (six PPstimulated rats and four KA type 2 rats) at the origin of the $x$ - to $y$-axes, and the more scattered distribution of all controls and KA type 1 animals, suggests that translamellar disinhibition was uniquely associated with extensive hilar cell loss, whereas partial hilar cell loss produced no obvious granule cell disinhibition (Fig.
7), as demonstrated previously by Milgram et al. (1991). Table 1 presents quantitative data showing that, at longitudinal distances $>2.5 \mathrm{~mm}$, which were not significantly different between groups, the four KA type 2 rats and all six PP-stimulated rats exhibited statistically significant differences in second population spike suppression compared with controls and KA type 1 animals.

\section{Longitudinal associational projections of hippocampal inhibitory interneurons}

Despite our hypothesis that longitudinally projecting hilar mossy cells evoke translamellar inhibition by exciting inhibitory neurons (Sloviter, 1991, 1994), the simplest explanation for the observed translamellar inhibition was that locally activated inhibitory interneurons directly inhibited distant granule cells. Therefore, we determined the relative extent of the longitudinal projections of hilar mossy cells and hippocampal inhibitory interneurons by focally injecting the retrograde tracer FG into the anterior recording site and then assessing the subsequently labeled neuron populations at the BMI site $\sim 2.5-4 \mathrm{~mm}$ in the posterior (temporal) direction.

FG injection produced a large FG-labeled region that involved all dentate gyrus laminas and the CA1 region above the injection target site, as illustrated previously (Zappone and Sloviter, 2001). In sections at the outer edge of the FG injection site (Fig. $8 \mathrm{~A}$ ), all hippocampal principal cells and interneuron subpopulations were FG positive, indicating an ability of all neuronal subpopulations to sequester FG intracellularly. The most notable and consistent feature of associational transport of FG was the precipitous decline in FG staining of inhibitory interneurons in all hippocampal subregions at longitudinal distances $>500 \mu \mathrm{m}$ from the outer edge of the FG injection site (Fig. 9, compare $A 1, A 2)$. Although sections progressively farther from the FG injection site exhibited extensive FG labeling of dentate hilar neurons (Figs. 8C, 9A2, 10), GAD67-positive inhibitory interneurons of the dentate molecular and granule cell layers were conspicuously and consistently FG negative only several hundred micrometers from the outer edge of the FG injection site. The consistent lack of distant FG transport (Figs. 8C, 9A2) by any presumed dentate basket cells of the granule cell layer, or by axo-axonic chandelier cells of the molecular layer (Freund and Buzsáki, 1996), was assessed quantitatively after colocalization of FG and GAD67 immunoreactivities. Of 573 GAD67-positive interneurons of the dentate granule cell and molecular layers counted in 18 sections that were $\sim 480-1920 \mu \mathrm{m}$ from the FG injection sites in three rats, only one cell was judged to be FG positive, and this cell was located $\sim 480 \mu \mathrm{m}$ from the injection site. Thus, no GAD67-positive interneurons $>0.5 \mathrm{~mm}$ from the FG injection site were FG labeled in three animals in which most hilar neurons were intensely FG positive $>4 \mathrm{~mm}$ longitudinally.

In the hippocampus proper, the steep longitudinal decline in FG labeling of interneurons included the large populations of hippocampal interneuron somata in strata oriens, radiatum, and lacunosum-moleculare (Fig. 9A,A2). One consistent exception was a small number of intensely FG-immunolabeled interneu- 


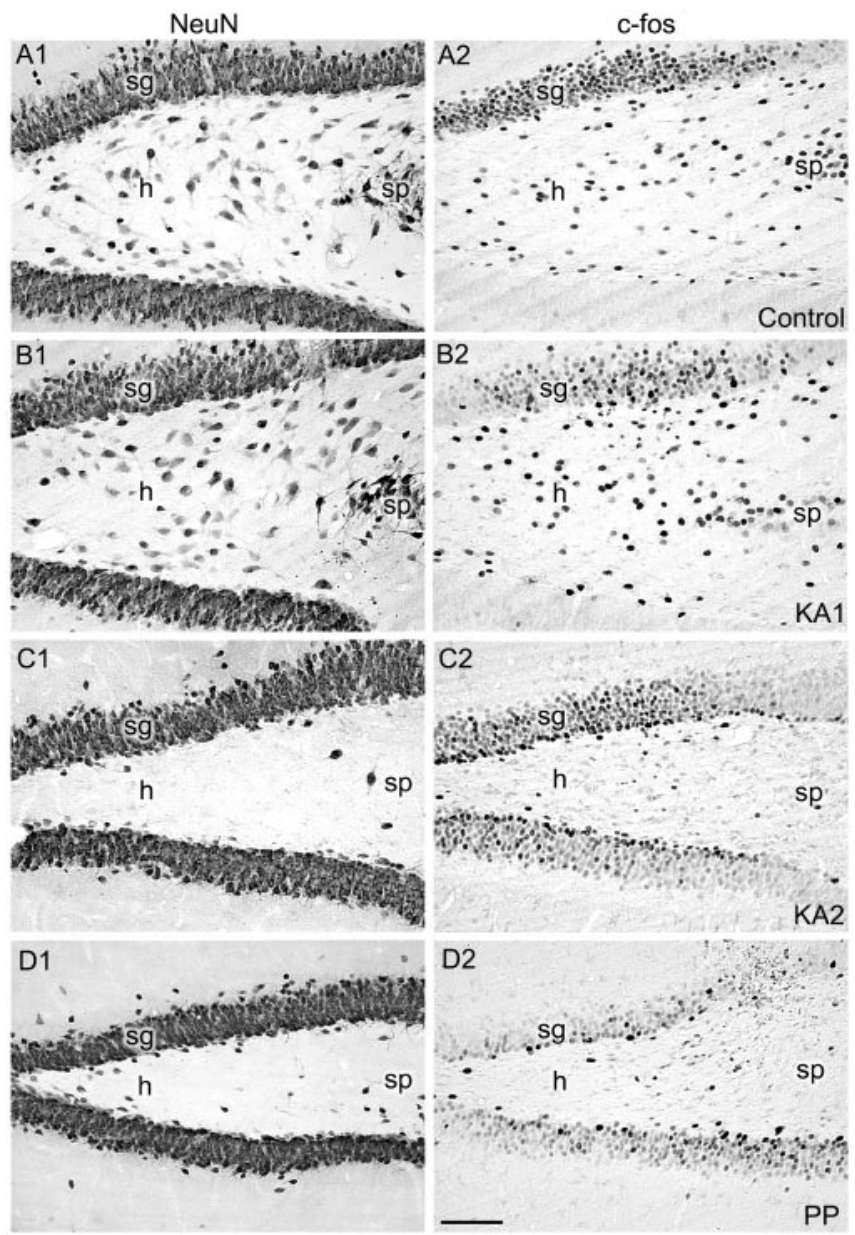

E

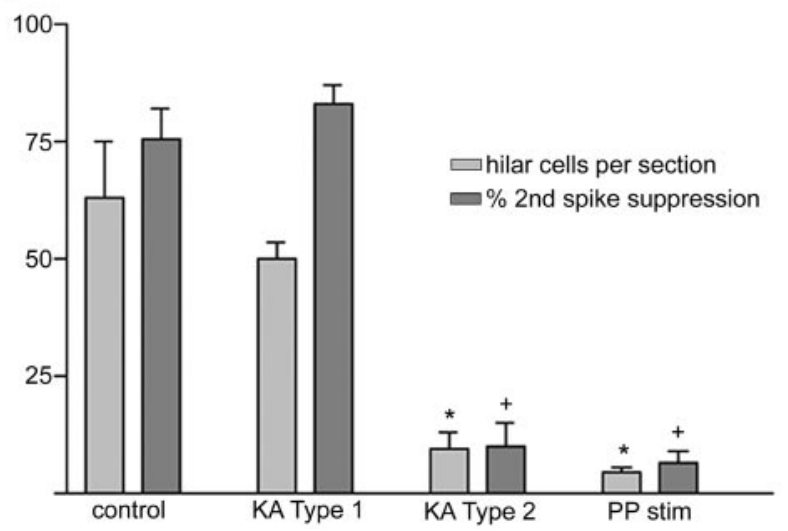

Figure 5. Hilar neuron loss and c-Fos expression $3 \mathrm{~d}$ after KA-induced SE or $24 \mathrm{hr}$ intermittent PP stimulation. A1, NeuN immunoreactivity (a neuronal marker) in the dentate gyrus of a saline-treated control rat, illustrating the normal neuronal constituents of the dentate granule cell layer (sg, stratum granulosum), the hilus ( $h$ ), and the adjacent end of the CA3c pyramidal cell layer (sp, stratum pyramidale). A2, c-Fos expression in the region of the BMI electrode, showing c-Fos-positive nuclei in cells of all dentate subregions. B1, B2, NeuN and c-Fos expression in a KA-treated rat that exhibited intact translamellar inhibition (type 1 response). Note the persistence of NeuN and c-Fos immunoreactivity in the hilus, which in $10 \mathrm{KA}$ type 1 animals involved an average of 20\% fewer hilar neurons counted (range, 10-38\%) compared with controls. C1, C2, NeuN and c-Fos expression in an identically KA-treated rat that exhibited a loss of translamellar inhibition (type 2 response). Note extensive hilar neuron loss (an average of $85 \%$ hilar cell loss; $n=4$; range, $68-94 \%$ ). D1, D2, NeuN and c-Fos expression $3 \mathrm{~d}$ after $24 \mathrm{hr}$ of PP stimulation, which resulted in a failure to evoke translamellar inhibition despite effective BMI-induced activation of granule cells (Fig. 4(3). In six PP-stimulated animals, the average hilar neuron loss was 93\% (range, 89-95\%). E, Graph showing the correlation between BMIinduced suppression of the second evoked population spike amplitude recorded at the saline rons at the stratum radiatum/lacunosum-moleculare border and in the stratum oriens (Fig. 9A2). Thus, our ability to detect intense FG immunoreactivity in a small number of interneurons relatively far $(>2 \mathrm{~mm})$ from the FG injection site indicates the effectiveness of the methods we used to detect FG in interneurons and demonstrates that the vast majority of interneurons, including all basket cell somata of all hippocampal principal cell layers, did not transport even a minimally detectable concentration of FG 2-4 mm from the injection site. Results of the FG control injections indicated that the FG labeling of dentate gyrus neurons was the result of site-specific transport of FG from the dentate gyrus injection site. Neither FG injection into area CA1 above the dentate gyrus, nor into the neocortex above the dentate gyrus, labeled any dentate gyrus neurons.

As described previously after injection of retrograde tracer into the anterior hippocampus (Qiu and Han, 1995; Buckmaster and Jongen-Rêlo, 1999), the principal location of the vast majority of retrogradely labeled, longitudinally projecting neurons was the dentate hilus (Fig. 8C), which contains both excitatory mossy cells (Amaral, 1978; Ribak et al., 1985; Soriano and Frotscher, 1994) and a variety of intermingled inhibitory interneurons (Amaral, 1978; Freund and Buzsáki, 1996). To determine whether FG-labeled hilar neurons included a significant number of inhibitory interneurons capable of directly mediating translamellar inhibition, we colocalized FG with GluR2, which primarily labels mossy cells (Leranth et al., 1996), with SS, which labels the largest population of hilar inhibitory interneurons (Bakst et al., 1986; Sloviter and Nilaver, 1987), and with PV, which labels several inhibitory interneuron populations in all dentate subregions (Freund and Buzsáki, 1996; Sloviter et al., 2003).

Quantitative analysis of sections progressively distant from the FG injection site revealed that the proportion of hilar FGpositive neurons that were also GluR2 positive increased as the distance from the tracer injection site increased, whereas the proportion of FG-labeled neurons that were SS or PV positive decreased progressively and precipitously (Fig. 10). Within the region $~ 2.2-2.9 \mathrm{~mm}$ from the edge of the FG injection site, $81 \%$ of all GluR2-positive hilar neurons ( 465 of 573 neurons) were FG labeled. Within this same region, $\sim 6 \%$ of all FG-labeled neurons were SS positive. These few FG-labeled hilar interneurons constituted $\sim 5 \%$ of the SS-positive hilar neuron population ( 36 of 679 SS-positive hilar neurons) in the sections from this longitudinal segment. In addition, virtually all of the few FG-labeled, SSpositive hilar neurons that we detected were only weakly FG positive, whereas GluR2-positive neurons in adjacent, coprocessed sections were intensely FG immunopositive (Fig. 10A). Farther along the longitudinal axis $(\sim 3.2-3.9 \mathrm{~mm})$, the percentage of SS-positive neurons that was FG labeled decreased to $\sim 2 \%$ ( 22 of 965 SS-positive neurons). Consistent with these results, indicating minimal FG labeling of distant hilar SS- and GAD67-positive dentate interneurons, PV-positive neurons were consistently FG negative $>0.5 \mathrm{~mm}$ from the FG injection site (Fig. 10).

\section{$\leftarrow$}

electrode and the number of hilar neurons surviving at the septo-temporal level of the BMI electrode. The group means for cell number $\left({ }^{*}\right)$ and the degree of second spike suppression $(+)$ in both the KA type 2 and PP stimulation groups were significantly different from the control and KA type 1 groups ( $p<0.05$ ); the latter were not significantly different from each other $(p>0.05)$. Scale bar, $100 \mu \mathrm{m}$. Magnification, $64 \times$. 


\section{Retrograde labeling of SS-positive hilar neurons after septal or hippocampal FG injection}

Given the consistently infrequent and weak FG labeling of SS-positive hilar interneurons after intrahippocampal FG injection, we next determined whether these interneurons lack the ability to transport FG in concentrations that result in intense labeling. This experiment addressed the possibility that SS-positive hilar interneurons might have extensive associational projections, as suggested by Buckmaster and Schwartzkroin (1995), yet be incapable of transporting FG in detectable quantities for unknown biological reasons. To answer this question, we exploited our recent observation that hilar SS-positive interneurons send axonal projections to the septum (Zappone and Sloviter, 2001). Injection of FG into the medial septum $(n=$ 6) consistently resulted in intense FG labeling of many hilar SS-positive interneurons throughout the longitudinal axis of the hippocampus (Fig. 11B1), and SS-like immunoreactivity was detectable in virtually all of these septally projecting, FGpositive interneurons. For hilar SSpositive somata in the ventral dentate gyrus, this represents transport of FG over a distance of $\sim 10 \mathrm{~mm}$ from the FG injection site. Conversely, injection of the same volume of the same FG solution into the hippocampus failed to similarly label SSpositive interneurons $1-3 \mathrm{~mm}$ along the longitudinal axis. Thus, the lack of detectable FG in the vast majority of SS-positive hilar interneurons after relatively nearby FG injection into the hippocampus was not the result of an inability of these hilar interneurons to take up or transport FG from distant sites.

\section{Discussion}

The main findings of this study are, first, that the net translamellar influence of focal granule cell discharges on distant granule cells was inhibition, not excitation. Second, translamellar inhibition was abolished by $\mathrm{SE}$ whenever extensive hilar neuron loss resulted and by prolonged PP stimulation, which consistently produced extensive hilar neuron loss but minimal extrahippocampal damage. Third, retrograde tracing indicated that: (1) mossy cells form extensive longitudinal axon projections spanning the distance over which translamellar inhibition was evoked; (2) basket cells and chandelier cells appear to have extremely limited longitudinal axonal projections; and (3) with rare exceptions, SS-positive interneurons form sparse and longitudinally limited axonal projections, despite sending extensive projections to the more distant septum.

\section{Translamellar inhibition rather than excitation}

Although mossy cells have been hypothesized to constitute a recurrent excitatory system that links distant granule cells together (Amaral and Witter, 1989; Buckmaster and Schwartzkroin, 1994), we detected only distant inhibition after focal granule cell discharge. Relatively weak longitudinal excitation has been reported (Bekenstein and Lothman, 1991; Hetherington et al.,
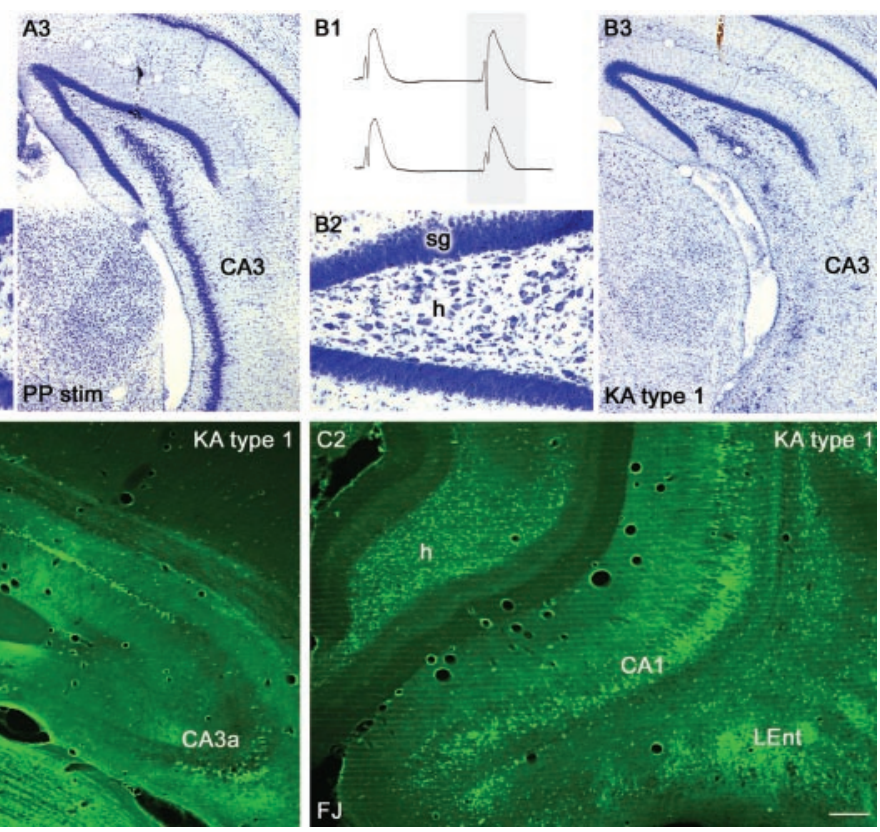

Figure 6. Loss or survival of dorsal hippocampal hilar neurons corresponds to loss or preservation of translamellar inhibition. $A$, 作

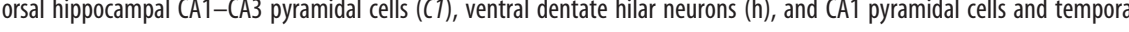

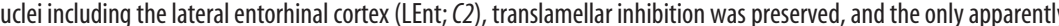
undamaged hippocampal region in this animal was the dorsal dentate gyrus ( $C 1$, asterisk). Calibration: $A 1-B 2,5 \mathrm{mV}$ and $10 \mathrm{msec}$. Scale bar: $A 2, B 2,100 \mu \mathrm{m} ; A 3, B 3,356 \mu \mathrm{m} ; C 1, C 2,237 \mu \mathrm{m}$. Magnification: $A 2, B 2,46 \times ; A 3, B 3,14 \times ; C 1, C 2,19 \times$.

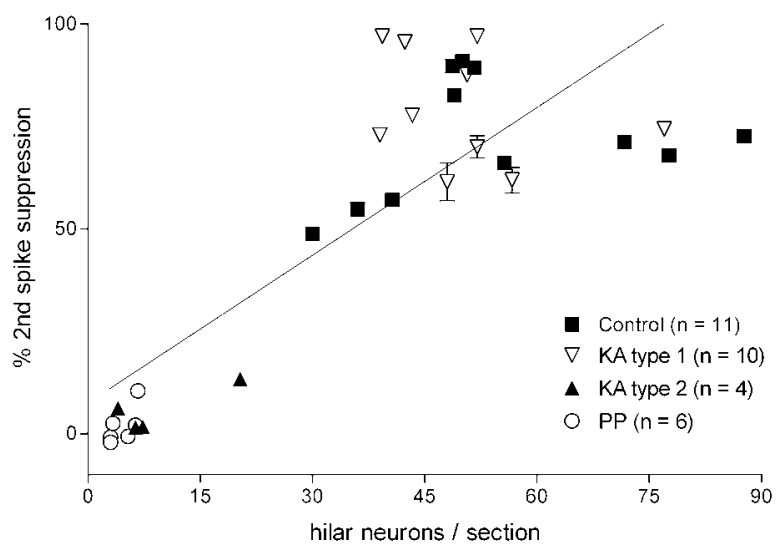

Figure 7. Correlation between hilar neuron loss and loss of translamellar inhibition. The average number of Nissl-stained hilar neurons per section from each of 31 rats tested is plotted against the percentage of suppression of the second of two granule cell population spikes evoked by PP stimulation at $0.3 \mathrm{~Hz}$ in control, KA-treated, and $24 \mathrm{hr}$ PP-stimulated rats. There was a correlation between the number of hilar neurons and the degree of second spike suppres$\operatorname{sion}\left(r^{2}=0.68\right)$. Although the data display a somewhat linear relationship, there was a distinct clustering of data points. All rats that exhibited a failure of translamellar inhibition (4 KA type 1 and all 6 PP-stimulated rats) were subsequently found to have extensive hilar neuron loss and were clustered close to the origin of the $x$ - to $y$-axes. Conversely, all control and KA type 1 rats exhibited intact second spike suppression and relative hilar neuron preservation.

1994), but the use of electrical stimulation in these studies makes it difficult to identify the intrinsic pathways or fibers of passage mediating responses recorded within the same stimulated structure. These problems of interpretation led us to use the BMI 

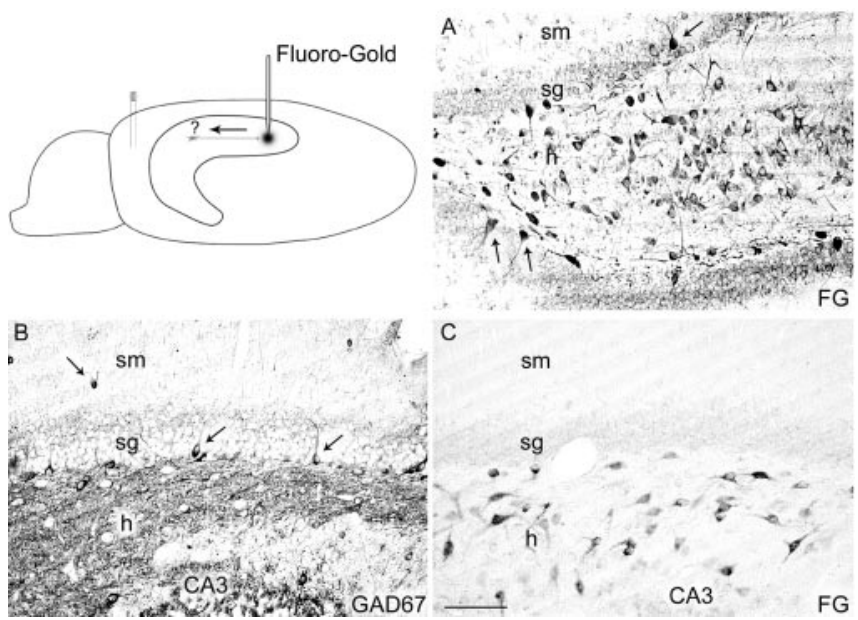

Figure 8. Retrograde transport of $\mathrm{FG}$ from the saline electrode site to the BMI electrode site. The retrograde tracer $\mathrm{FG}$ was used to identify the hippocampal neuron subtypes with axonal projections spanning the longitudinal distance over which translamellar inhibition was evoked. $A$, At the approximate outer edge of the FG injection zone, all neuronal subpopulations in the dentate gyrus were FG immunopositive, including granule cells, hilar neurons ( $\mathrm{h}$ ), and presumed interneurons of the granule cell layer [arrows in stratum granulosum (sg)]. B, C, GAD67and FG-immunostained sections, respectively, at the $\sim 3.0 \mathrm{~mm}$ longitudinally distant site showing the location of GAD67-positive interneurons in the granule cell and molecular (sm, stratum moleculare) layers (arrows), which were consistently FG negative (C). Scale bar, 100 $\mu \mathrm{m}$. Magnification, $65 \times$.

diffusion method (Steward et al., 1990; Sloviter and Brisman, 1995) to evoke focal granule cell discharge without electrical stimulation. If synchronously activated, longitudinally projecting mossy cells directly excited distant granule cells, a summated potential analogous to those evoked by PP stimulation should have been generated at the appropriate latencies at the distant recording site. However, the same focal discharges that powerfully inhibited distant granule cells produced no evidence of distant granule cell excitation.

These results are consistent with previous conclusions that inhibitory interneurons are the primary targets of the excitatory associational-commissural pathway, which also produced commissural granule cell inhibition rather than excitation (Buzsáki and Eidelberg, 1982; Douglas et al., 1983). The mechanism by which mossy cells might excite inhibitory neurons more powerfully than they excite granule cells may be similar to that reported in studies of CA1 interneurons, which express GluR5 subunits of KA-preferring glutamate receptors. CA1 inhibitory interneurons were shown to be activated powerfully by KA, resulting in pyramidal cell inhibition (Cossart et al., 1998; Frerking et al., 1998; Bureau et al., 1999). Conversely, CA1 pyramidal cells exhibit minimal GluR5 subunit expression and were not excited directly by KA receptor activation (Melyan et al., 2002). In the dentate gyrus, KA receptors are concentrated in the exact location in which mossy cell axons terminate (Monaghan and Cotman, 1982); granule cells, like CA1 pyramidal cells, lack GluR5 subunits; and dentate inhibitory interneurons express the GluR5 subunit (Bureau et al., 1999; Paternain et al., 2000). If the differential effects of KA receptor activation in the CA1 region are manifested similarly in the dentate gyrus, mossy cells may preferentially excite distant inhibitory neurons, causing granule cell inhibition. This scenario is consistent with the location and expression pattern of KA receptor subunits in both dentate granule cells and interneurons and our results demonstrating translamellar inhibition, rather than excitation.
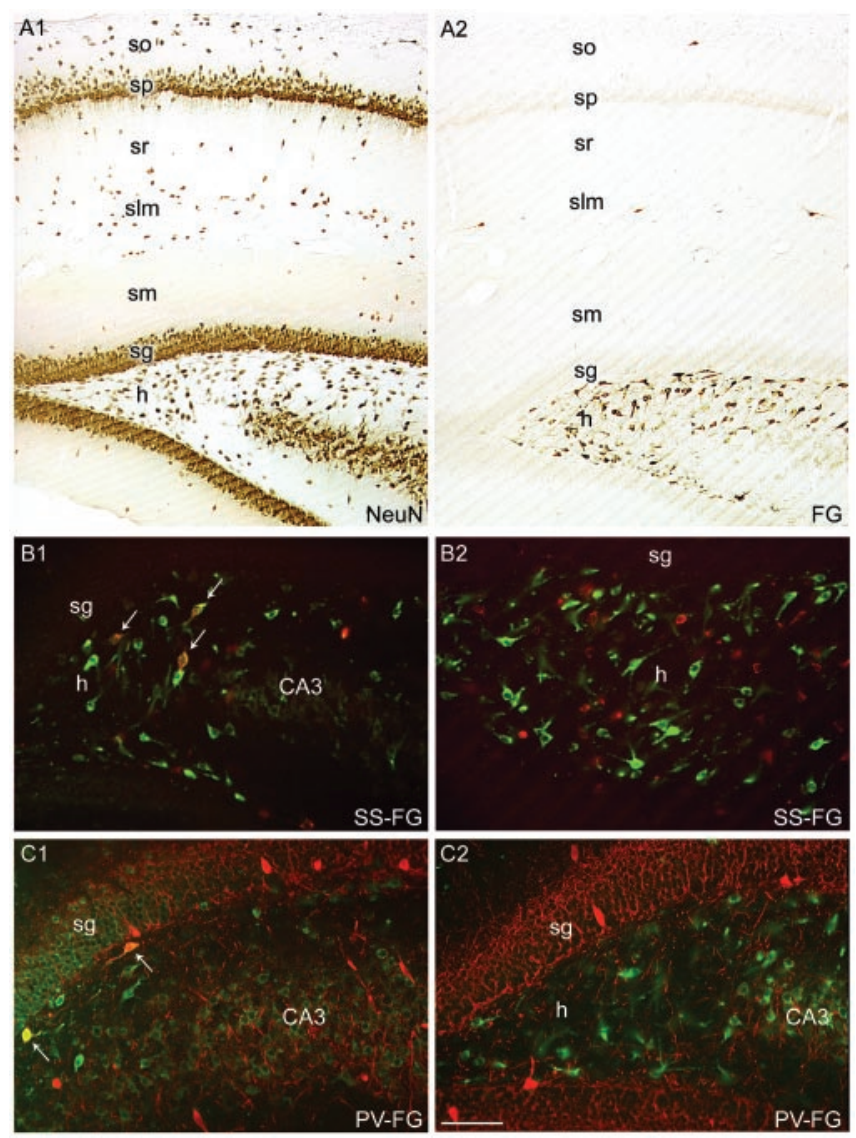

Figure 9. Limited longitudinal transport of the retrograde tracer FG by hippocampal interneurons. A1, Immunocytochemical localization of the neuronal marker NeuN shows the normal location and number of hippocampal principal cells and interneurons in the dorsal hippocampus. A2, In a section $\sim 3.2 \mathrm{~mm}$ distant from the rostral FG injection site, FG-immunopositive cells consistently included numerous hilar neurons (h) and a small number of interneurons of the stratum lacunosum-moleculare (slm) and stratum oriens (so) but not interneurons of the principal cell layers, stratum radiatum (sr), or the dentate molecular layer (sm). Note that the three sIm interneurons shown in $A 2$ were the largest number of area CA1 interneurons per section seen in any section analyzed. B1, Close to the FG injection site ( $~ 360 \mu \mathrm{m}$ longitudinally), FG-labeled cells (green) include SS-positive hilar interneurons (red), which appear orange or yellow when colocalized (arrows). B2, Sections $\sim 3.6 \mathrm{~mm}$ from the FG injection site rarely exhibited colocalization of SS and FG (Fig. 10, graph). (1, Colocalization of FG and PV similarly indicates that although PV-positive inhibitory interneurons immediately adjacent to the FG injection site colocalize FG (arrows), even slightly more distant PV-positive cells within the same section do not transport detectable FG. C2, Approximately $720 \mu \mathrm{m}$ from the FG injection site, PV-positive interneurons were not colocalized with FG. Scale bar: $A 1, A 2,200 \mu \mathrm{m}$; $B, C, 100 \mu \mathrm{m}$. Magnification: $A 1, A 2,33 \times ; B, C, 65 \times$.

\section{Translamellar disinhibition as a possible consequence of hilar neuron loss}

That the translamellar disinhibition we observed in lesioned animals was attributable to hilar neuron loss, rather than other effects of prolonged SE, is supported by the observation that all KA-treated rats exhibited SE lasting $>3 \mathrm{hr}$, and all exhibited hippocampal and extrahippocampal damage. The main difference we detected between KA-treated rats with intact or impaired translamellar inhibition was the extent of hilar cell loss. More conclusively, identical translamellar disinhibition was reproduced by prolonged PP stimulation, which reliably produced extensive hilar neuron loss but little other damage. However, other undetected effects of prolonged granule cell discharges that might uniquely parallel hilar neuron injury, such as downregulation of $\mathrm{GABA}_{\mathrm{A}}$ receptors in granule cells (Brooks-Kayal et al., 1998), cannot be excluded as alternate explanations. 
Our finding that only extensive hilar cell loss was reliably associated with translamellar disinhibition explains why a previous study failed to observe translamellar disinhibition in KA-treated rats (Buckmaster and Dudek, 1997). These authors used animals that exhibited only partial hilar neuron loss (corresponding to our KA type 1 animals) and assessed lateral inhibition only $1 \mathrm{~mm}$ from the BMI electrode, two factors that negate their conclusion that mossy cells do not activate longitudinally distant inhibitory neurons. Given that bicuculline diffuses $\sim 400-500 \mu \mathrm{m}$ toward the saline electrode, lateral inhibition recorded only $1 \mathrm{~mm}$ from the BMI electrode, as we originally described it (Sloviter and Brisman, 1995), likely reflects local intralamellar lateral inhibition rather than translamellar inhibition (Sloviter, 1994). Any activity recorded at the short distance assessed by Buckmaster and Dudek (1997) is unlikely to involve associational projections of mossy cells, regardless of the extent of mossy cell loss, because mossy cell innervation of the dentate inner molecular layer specifically avoids the $\sim 1 \mathrm{~mm}$ radius surrounding their somata (Amaral and Witter, 1989; Buckmaster et al., 1996).

\section{Longitudinal projections of dentate inhibitory interneurons}

The identity of neurons capable of mediating translamellar inhibition was addressed by our retrograde transport studies, which confirmed that mossy cells are the only dentate neuron population with significant longitudinal projections spanning $\sim 2.5-4.5$ mm longitudinally (Amaral and Witter, 1989). Although longitudinally projecting inhibitory interneurons could contribute to translamellar granule cell inhibition, the results of the present and all previous anterograde and retrograde tracing studies in rats suggest that associational projections of inhibitory interneurons are minimal beyond a longitudinal distance of $1 \mathrm{~mm}$ (Amaral and Witter, 1989; Qiu and Han, 1995; Buckmaster and Jongen-Rêlo, 1999). This seems particularly true for basket cells and chandelier cells, which powerfully inhibit principal cell somata and axon initial segments (Freund and Buzsáki, 1996), in that these interneurons of the granule cell and molecular layers only transported FG locally. Consistent with our results, studies of tracer-filled interneurons indicate that hilar inhibitory interneurons most densely innervate targets closest to their somata, with total interneuron axon length per segment decreasing precipitously between 0.5 and $1 \mathrm{~mm}$ from the soma (Buckmaster and Schwartzkroin, 1995; Sik et al., 1997). In this regard, the observation that inhibitory interneurons cluster most of their axon length on targets closest to their somata seems of greater functional significance than the observation that a small fraction of the total interneuron axon length can sometimes extend $>1 \mathrm{~mm}$ longitudinally. The complementary termination patterns of interneurons and mossy cells, which involve inhibitory interneuron terminals concentrated within the region preferentially avoided by mossy cell axons (Amaral and Witter, 1989; Sik et al., 1997), would appear to be entirely consistent with lamellar organization. Thus, we do not view sparse longitudinal projections of a few hilar inhibitory interneurons to be an indication that hilar inhibitory interneurons have far-reaching, functionally significant translamellar influences, as suggested by Buckmaster and Schwartzkroin (1995). To the contrary, the observation that most of the axon arbor of hilar inhibitory interneurons terminates on local targets is strongly supportive of the conclusion that the axonal projections of hilar SS-positive interneurons, and virtually all other inhibitory neurons, are fundamentally "lamellar" in distribution.

\section{Possible functional implications}

Lamellar function may be established by inhibitory interneurons acting locally to focus strong excitation to local targets (intralamellar lateral inhibition) and by mossy cells establishing lateral inhibition in surrounding lamellae to increase the "signal-tonoise" ratio. Our finding that few inhibitory interneurons were FG labeled by relatively close FG injections suggests that inhibitory interneurons in one segment are unlikely to contribute significantly to lateral inhibition in distant segments. However, given the observation that individual inhibitory interneurons can have widely divergent influences on large numbers of principal cells (Cobb et al., 1995), inferences drawn primarily from anatomical data do not eliminate the possibility that small numbers of inhibitory interneurons might directly contribute to translamellar inhibition.

Regardless of which cell types and synaptic mechanisms mediate translamellar inhibition in the dentate gyrus, the present data support the concept of functional separation in the granule cell layer as a consequence of inhibitory translamellar impulses (Andersen et al., 1966; Struble et al., 1978; Sloviter, 1994; Sloviter and Brisman, 1995). Thus, we do not share the view that the existence of excitatory longitudinal projections is necessarily antithetical to the concept of individual hippocampal lamellae functioning independently (Amaral and Witter, 1989). Presumably, the functional effects of the longitudinal projections, rather than their existence or their excitatory nature, determine their physiological influence. That these projections seem powerfully inhibitory in nature in vivo supports the lamellar hypothesis of hippocampal organization as it applies to the dentate gyrus (Andersen et al., 1971, 2000; Moser and Moser, 1998; Hampson et al., 1999).

Finally, an extensive loss of hilar inhibitory interneurons (deLanerolle et al., 1989) and excitatory hilar mossy cells (Blümcke et al., 2000) occurs in many patients with temporal lobe epilepsy, which is, in some cases, the only pathology evident anywhere within the epileptic human brain (Margerison and Corsellis, 1966). Thus, the loss of translamellar inhibition that 


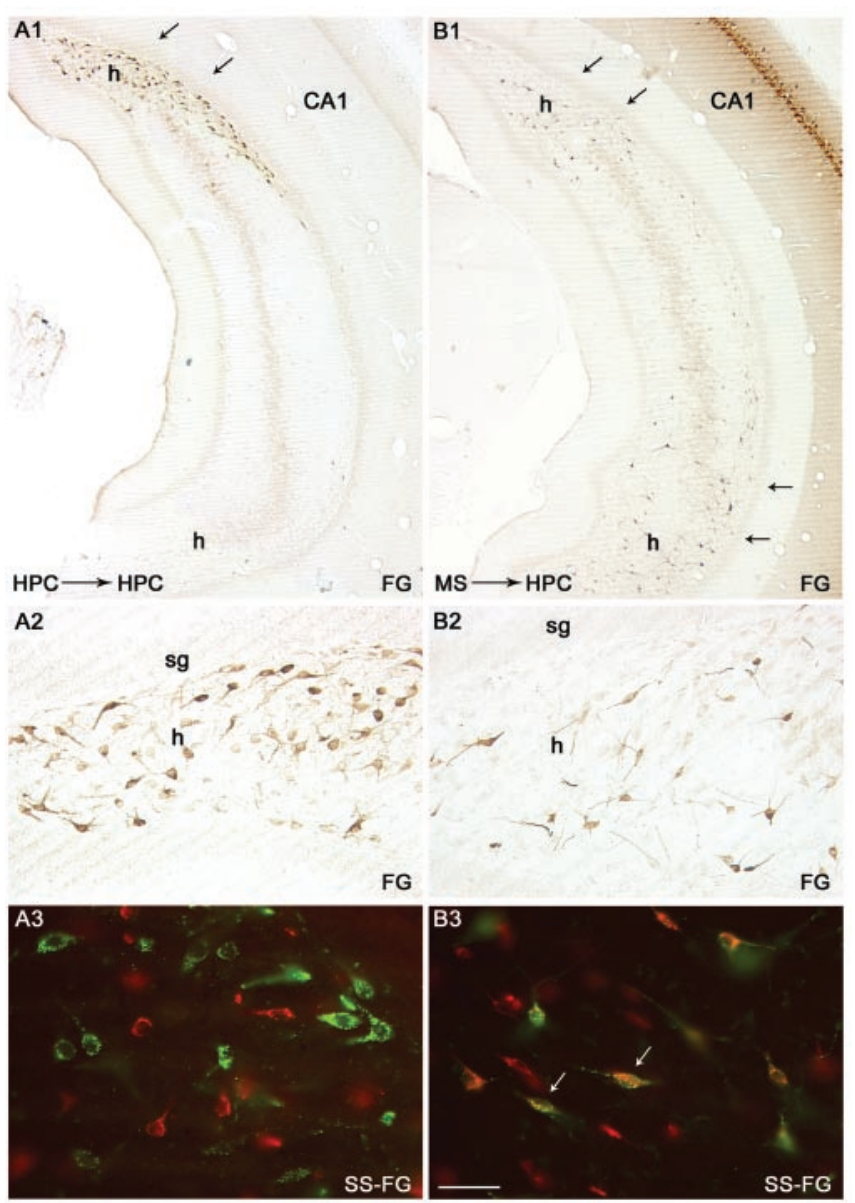

Figure 11. Retrograde transport of $\mathrm{FG}$ by dentate hilar neurons after $\mathrm{FG}$ injection into the rostral hippocampus or the medial septum. $A 1, A 2$, After FG injection into the rostral hippocampus, hilar neurons were labeled $\sim 2-4 \mathrm{~mm}$ caudally. However, hilar SS-positive interneurons ( $A 3$; red) were rarely $\mathrm{FG}$ positive (green) at longitudinal distances at which translamellar inhibition was evoked. $B 1, B 2$, After injection of $F G$ into the septum, numerous hilar interneurons throughout the longitudinal axis of the hippocampus (arrows) were intensely FG immunopositive, as were CA1 pyramidal cells and interneurons. B3, After FG injection into the septum, virtually all FG-labeled hilar neurons were $\mathrm{SS}$ immunoreactive (red). These results indicate that hilar SS-positive interneurons have the capacity to transport FG from a distant site (medial septum; $\sim 6-10 \mathrm{~mm}$ distant) in concentrations that result in intense $F G$ labeling but that these same interneurons do not transport even minimally detectable $\mathrm{FG}$ from significantly closer injection sites within the hippocampus. Scale bar: $A 1, B 1,508 \mu \mathrm{m} ; A 2, B 2,100 \mu \mathrm{m} ; A 3, B 3,50$ $\mu \mathrm{m}$. Magnification: $A 1, B 1,13 \times ; A 2, B 2,64 \times ; A 3, B 3,130 \times$.

reliably follows extensive hilar neuron loss suggests that the loss of both local and longitudinal inhibitory influences may disrupt lamellar function, and underlie postinjury hippocampal network dysfunction related to amnestic conditions and seizure disorders.

\section{References}

Amaral DG (1978) A Golgi study of cell types in the hilar region of the hippocampus in the rat. J Comp Neurol 182:851-914.

Amaral DG, Witter MP (1989) The three-dimensional organization of the hippocampal formation: a review of anatomical data. Neuroscience 31:571-591.

Andersen P, Holmqvist B, Voorhoeve PE (1966) Entorhinal activation of dentate granule cells. Acta Physiol Scand 66:448-460.

Andersen P, Bliss TVP, Skrede KK (1971) Lamellar organization of hippocampal excitatory pathways. Exp Brain Res 13:222-238.

Andersen P, Soleng AF, Raastad M (2000) The hippocampal lamella hypothesis revisited. Brain Res 886:165-171.

Bakst I, Avendano C, Morrison JH, Amaral DG (1986) An experimental analysis of the origins of somatostatin-like immunoreactivity in the dentate gyrus of the rat. J Neurosci 6:1452-1462.

Bekenstein JW, Lothman EW (1991) Electrophysiological characterization of associational pathway terminating on dentate gyrus granule cells in the rat. Hippocampus 1:399-404.

Blümcke I, Suter B, Behle K, Kuhn R, Schramm J, Elger CE, Wiestler OD (2000) Loss of hilar mossy cells in Ammon's horn sclerosis. Epilepsia 41 [Suppl 6]:S174-S180.

Brooks-Kayal AR, Shumate MD, Jin H, Rikhter TY, Coulter DA (1998) Selective changes in single cell GABA(A) receptor subunit expression and function in temporal lobe epilepsy. Nat Med 4:1166-1172.

Buckmaster PS, Dudek FE (1997) Network properties of the dentate gyrus in epileptic rats with hilar neuron loss and granule cell axon reorganization. J Neurophysiol 77:2685-2696.

Buckmaster PS, Dudek FE (1999) In vivo intracellular analysis of granule cell axon reorganization in epileptic rats. J Neurophysiol 81:712-721.

Buckmaster PS, Jongen-Rêlo AL (1999) Highly specific neuron loss preserves lateral inhibitory circuits in the dentate gyrus of kainate-induced epileptic rats. J Neurosci 19:9519-9529.

Buckmaster PS, Schwartzkroin PA (1994) Hippocampal mossy cell function: a speculative view. Hippocampus 4:393-402.

Buckmaster PS, Schwartzkroin PA (1995) Interneurons and inhibition in the dentate gyrus of the rat in vivo. J Neurosci 15:774-789.

Buckmaster PS, Wenzel HJ, Kunkel DD, Schwartzkroin PA (1996) Axon arbors and synaptic connections of hippocampal mossy cells in the rat in vivo. J Comp Neurol 366:271-292.

Bureau I, Bischoff S, Heinemann SF, Mulle C (1999) Kainate receptormediated responses in the CA1 field of wild-type and GluR6-deficient mice. J Neurosci 19:653-663.

Buzsáki G, Eidelberg E (1982) Direct afferent excitation and long-term potentiation of hippocampal interneurons. J Neurophysiol 48:597-607.

Cobb SR, Buhl EH, Halasy K, Paulsen O, Somogyi P (1995) Synchronization of neuronal activity in hippocampus by individual GABAergic interneurons. Nature 378:75-78.

Cossart R, Esclapez M, Hirsch JC, Bernard C, Ben-Ari Y (1998) GluR5 kainate receptor activation in interneurons increases tonic inhibition of pyramidal cells. Nat Neurosci 1:470-478.

deLanerolle NC, Kim JH, Robbins RJ, Spencer DD (1989) Hippocampal interneuron loss and plasticity in human temporal lobe epilepsy. Brain Res 495:387-395.

Douglas RM, McNaughton BL, Goddard GV (1983) Commissural inhibition and facilitation of granule cell discharge in fascia dentata. J Comp Neurol 219:285-294.

Frerking M, Malenka RC, Nicoll RA (1998) Synaptic activation of kainate receptors on hippocampal interneurons. Nat Neurosci 1:479-486.

Freund TF, Buzsáki G (1996) Interneurons of the hippocampus. Hippocampus 6:347-470.

Hampson RE, Simeral JD, Deadwyler SA (1999) Distribution of spatial and nonspatial information in dorsal hippocampus. Nature 402:610-614.

Hetherington PA, Austin KB, Shapiro ML (1994) Ipsilateral associational pathway in the dentate gyrus: an excitatory feedback system that supports $\mathrm{N}$-methyl-D-aspartate-dependent long-term potentiation. Hippocampus 4:422-438.

Leranth C, Szeidemann Z, Hsu M, Buzsáki G (1996) AMPA receptors in the rat and primate hippocampus: a possible absence of GluR2/3 subunits in most interneurons. Neuroscience 70:631-652.

Margerison JH, Corsellis JA (1966) Epilepsy and the temporal lobes. A clinical, electroencephalographic and neuropathological study of the brain in epilepsy, with particular reference to the temporal lobes. Brain 89:499-530.

Melyan Z, Wheal HV, Lancaster B (2002) Metabotropic-mediated kainate receptor regulation of IsAHP and excitability in pyramidal cells. Neuron 34:107-114.

Milgram NW, Yearwood T, Khurgel M, Ivy GO, Racine R (1991) Changes in inhibitory processes in the hippocampus following recurrent seizures induced by systemic administration of kainic acid. Brain Res 551:236-246.

Monaghan DT, Cotman CW (1982) The distribution of [3H]kainic acid binding sites in rat CNS as determined by autoradiography. Brain Res 252:91-100.

Moser MB, Moser EI (1998) Functional differentiation in the hippocampus. Hippocampus 8:608-619.

Paternain AV, Herrera MT, Nieto MA, Lerma J (2000) GluR5 and GluR6 
kainate receptor subunits coexist in hippocampal neurons and coassemble to form functional receptors. J Neurosci 20:196-205.

Paxinos G, Watson C (1998) The rat brain in stereotaxic coordinates. San Diego: Academic.

Qiu K, Han ZS (1995) Local projections of GABAergic neurons in the dentate gyrus and CA1 region in the rat hippocampal formation. Brain Res 702:287-292.

Ribak CE, Seress L, Amaral DG (1985) The development, ultrastructure and synaptic connections of the mossy cells of the dentate gyrus. J Neurocytol 14:835-857.

Scharfman HE (1995) Electrophysiological evidence that dentate hilar mossy cells are excitatory and innervate both granule cells and interneurons. J Neurophysiol 74:179-194.

Schmued LC, Fallon JH (1986) Fluoro-Gold: a new fluorescent retrograde axonal tracer with numerous unique properties. Brain Res 377:147-154.

Schmued LC, Hopkins KJ (2000) Fluoro-Jade B: a high affinity fluorescent marker for the localization of neuronal degeneration. Brain Res 874:123-130.

Sik A, Penttonen M, Buzsáki G (1997) Interneurons in the hippocampal dentate gyrus: an in vivo intracellular study. Eur J Neurosci 9:573-588.

Sloviter RS (1983) "Epileptic" brain damage in rats induced by sustained electrical stimulation of the perforant path. I. Acute electrophysiological and light microscopic studies. Brain Res Bull 10:675-697.

Sloviter RS (1987) Decreased hippocampal inhibition and a selective loss of interneurons in experimental epilepsy. Science 235:73-76.

Sloviter RS (1991) Permanently altered hippocampal structure, excitability, and inhibition after experimental status epilepticus in the rat: the dormant basket cell hypothesis and its possible relevance to temporal lobe epilepsy. Hippocampus 1:41-66.

Sloviter RS (1994) The functional organization of the hippocampal dentate gyrus and its relevance to the pathogenesis of temporal lobe epilepsy. Ann Neurol 35:640-654.

Sloviter RS, Brisman JL (1995) Lateral inhibition and granule cell synchrony in the rat hippocampal dentate gyrus. J Neurosci 15:811-820.

Sloviter RS, Nilaver G (1987) Immunocytochemical localization of GABA-, cholecystokinin-, vasoactive intestinal polypeptide- and somatostatinlike immunoreactivity in the area dentata and hippocampus of the rat. J Comp Neurol 256:42-60.

Sloviter RS, Zappone CA, Harvey BD, Bumanglag AV, Bender RA, Frotscher M (2003) "Dormant basket cell" hypothesis revisited; relative vulnerabilities of dentate gyrus mossy cells and inhibitory interneurons after hippocampal status epilepticus in the rat. J Comp Neurol 459:44-76.

Soriano E, Frotscher M (1994) Mossy cells of the rat fascia dentata are glutamate-immunoreactive. Hippocampus 4:65-70.

Steward O, Tomasulo R, Levy WB (1990) Blockade of inhibition in a pathway with dual excitatory and inhibitory action unmasks a capability for LTP that is otherwise not expressed. Brain Res 516:292-300.

Struble RG, Desmond NL, Levy WB (1978) Anatomical evidence for interlamellar inhibition in the fascia dentata. Brain Res 152:580-585.

Sutula T, Zhang P, Lynch M, Sayin U, Golarai G, Rod R (1998) Synaptic and axonal remodeling of mossy fibers in the hilus and supragranular region of the dentate gyrus in kainate-treated rats. J Comp Neurol 390:578-594.

Wenzel HJ, Buckmaster PS, Anderson NL, Wenzel ME, Schwartzkroin PA (1997) Ultrastructural localization of neurotransmitter immunoreactivity in mossy cell axons and their synaptic targets in the rat dentate gyrus. Hippocampus 7:559-570.

Zappone CA, Sloviter RS (2001) Commissurally projecting inhibitory interneurons of the rat hippocampal dentate gyrus: a colocalization study of neuronal markers and the retrograde tracer Fluoro-Gold. J Comp Neurol 441:324-344. 